\title{
CADASTRO MUNICIPAL DE ESPAÇOS LIVRES URBANOS DE RIBEIRÃO PRETO (SP): ACESSO PÚBLICO, ÍNDICES E BASE PARA NOVOS INSTRUMENTOS E MECANISMOS DE GESTÃO
}

\author{
Perci Guzzo ${ }^{1}$, Regina Maria Alves Carneiro ${ }^{2}$, Hamilton de Oliveira Júnior ${ }^{3}$
}

\begin{abstract}
RESUMO
Os espaços livres urbanos públicos e potencialmente coletivos de Ribeirão Preto(SP) correspondem a aproximadamente $11,5 \%$ da área urbanizada do município, totalizando 16.083.927,77 $\mathrm{m}^{2}$ ou 1.608 hectares. Considerando os espaços livres essencialmente públicos, ou seja, aqueles sem restrições de acesso à população, bem como a condição de implantado ou urbanizado, obtêm-se um índice de $4,4 \mathrm{~m}^{2} / \mathrm{hab}$. O Cadastro Municipal de Espaços Livres Urbanos de Ribeirão Preto foi organizado com o objetivo de sistematizar as informações existentes no âmbito da Prefeitura Municipal em relação à quantidade, localização, tamanho e nível de implantação desses espaços na cidade e sub-distrito. Os resultados do trabalho têm se prestado a consultas constantes, quer de caráter técnico-científico ou técnico-administrativo, e serviram de base para o levantamento de custos de implantação e de manutenção de áreas verdes públicas. Trata-se, portanto, de importante instrumento urbanístico e de planejamento municipal.
\end{abstract}

Palavras-chave: Espaços livres, Áreas verdes públicas, Planejamento urbano.

\footnotetext{
${ }^{1}$ Ecólogo, Mestre em Geociências e Meio Ambiente, Secretaria Municipal de Planejamento e Gestão Ambiental, Ribeirão Preto, São Paulo, pguzzo@terra.com.br

2 Engenheira Florestal, Mestre em Saúde Pública, Secretaria Municipal de Planejamento e Gestão Ambiental, Ribeirão Preto, São Paulo, tuia@terra.com.br

${ }^{3}$ Engenheiro Agrônomo, Secretaria Municipal de Infra-estrutura, Ribeirão Preto, São Paulo, hmo94@terra.com.br
} 


\title{
THE RIBEIRÃO PRETO'S MUNICIPAL REGISTRATION OF URBAN OPEN SPACES: PUBLIC ACCESS, INDEX AND BASE TO NEWS INSTRUMENTS AND MECHANISMS OF MANAGEMENT
}

\begin{abstract}
The public urbane open spaces and potential collective from Ribeirão Preto (SP) have about $11,5 \%$ of 1.608 hectares urbane area. To take it to account, these public open spaces or without public restrictions, have a 4,4 m2/hab index. The "Ribeirão Preto's Municipal Registration of Urbane Open Spaces" objected to organize information about, amount, location, size and introduction level of public urbane open space. This study result from technical scientific or management consultation that based the introduction and management coasts of green opens spaces. Therefore, this study could be very important to a town planning.
\end{abstract}

Key-words: urbane open spaces, public green areas, urban planning 


\section{INTRODUÇÃO}

As áreas não edificadas de uma cidade, de propriedade pública ou particular, independente de sua destinação de uso, são chamadas de espaços livres urbanos. Os de propriedade pública, quando destinados à conservação ambiental e implantação da vegetação, associados ou não ao lazer público, são denominados de áreas verdes públicas. As áreas verdes particulares se diferenciam das públicas por não permitirem a si o acesso livre das pessoas. Há ainda aquelas de domínio público que oferecem restrições quanto à acessibilidade, caso dos campi de universidades públicas, denominadas potencialmente coletivas. As áreas verdes são, portanto, um tipo especial de espaço livre urbano onde os elementos fundamentais de composição são a vegetação e o solo livre de impermeabilização. Espaços não vegetados ou construídos para abrigar equipamentos de lazer e de infra-estrutura são encontrados em muitas praças, parques e jardins públicos, mas nem por isso deixam de se constituir em espaços livres de uso público. Apregoa-se que uma área verde deva ser constituída de pelo menos $70 \%$ do seu espaço por áreas vegetadas com solo permeável.

Considerando a necessidade de manter em Ribeirão Preto (distrito sede e sub-distrito de Bonfim Paulista) áreas verdes públicas em condições de exercer suas funções social, ecológica e estética, foi instaurado o Inquérito Civil n 268/2004 pelo Ministério Público do Estado de São Paulo, por meio de sua Promotoria de Justiça de Meio Ambiente, junto à Prefeitura Municipal de Ribeirão Preto (PMRP), por meio de sua Secretaria de Planejamento e Gestão Ambiental. Como primeira etapa do trabalho, coube à PMRP diagnosticar a situação dessas áreas na cidade, considerando quantidade e qualidade. Como parte deste trabalho, coube também o levantamento de custos visando a implantação, manutenção e conservação de novas áreas verdes públicas, considerando serviços terceirizados. Também investigamos, preliminarmente, as necessidades de reestruturação dos setores da PMRP para atender parte da implantação e manutenção dessas áreas. Assim, os resultados deste trabalho, desenvolvido nos anos de 2004 e 2005, foram organizados no relatório intitulado "Cadastro Municipal de Espaços Livres Urbanos e Estudos para Implantação, Manutenção e Conservação das Áreas Verdes Públicas em Ribeirão Preto, SP". O presente artigo versa somente sobre a primeira parte do relatório que é o Cadastro Municipal de Espaços Livres Urbanos. 


\section{MATERIAIS E MÉTODOS}

\section{Terminologia empregada}

Para agrupar os espaços livres quando às suas funções urbanísticas, foi adotada a seguinte tipologia:

a) Espaço livre urbano: todos os espaços da cidade em que não há edificações, ou espaços abertos para o céu. Termo mais abrangente e que engloba todos os tipos relacionados em seguida;

b) Praça pública: espaço livre urbano público destinado ao lazer ativo, contemplativo e ao convívio social, podendo ou não ser dotado de vegetação;

c) Parque urbano: espaço livre urbano público com dimensão quase sempre superior à de praças e jardins públicos, destinado ao lazer ativo e contemplativo, à conservação dos recursos naturais e à promoção da melhoria das condições ambientais da cidade. Alguns parques urbanos podem constituir-se também como unidades de conservação. Os parques lineares são aqueles formados pelas faixas de terra existentes ao longo de rios e lagos, também com funções recreativas e conservacionistas;

d) Área Verde Pública (AVP): espaço livre urbano público destinado em loteamento à implantação de vegetação e/ou conservação de vegetação natural ou implantada préexistentes, associado à destinação e implantação de equipamentos de lazer. Neste trabalho englobam os sistemas de lazer, os sistemas de recreio e as áreas verdes com número de cadastro de próprio municipal;

e) Cemitério: espaço livre urbano público com presença de vegetação implantada e possibilidade de uso contemplativo;

f) Campus universitário: espaço livre urbano potencialmente coletivo com possibilidade de uso público, mas com algumas restrições quanto à acessibilidade da comunidade.

Para agrupar os espaços livres de acordo com seu nível de implantação e sua possibilidade de uso público, foram adotadas as seguintes categorias:

a) Implantado ou urbanizado: área com tratamento paisagístico, constituída de infra-estrutura e equipamentos que permitem o acesso e a oportunidade de recreação ativa e contemplativa;

b) Semi-implantado ou semi-urbanizado: área que já recebeu e que mantém algum tratamento paisagístico, alguma infra-estrutura ou ainda, algum equipamento de lazer. As iniciativas feitas por moradores vizinhos, como implantação de campos de futebol, plantio de árvores frutíferas e instalação de bancos, por exemplo, entram nesta categoria; 
c) Não implantado ou não urbanizado: área que não recebeu nenhuma intervenção do Poder Público ou de iniciativa da comunidade. A conotação dessas áreas é, na maioria das vezes, de abandono, servindo como depósito de entulho e com presença de vegetação ruderal.

d) Com alteração de função: área que está sendo utilizada para atividade humana que não seja a de abrigar o uso público, modelar a paisagem urbana ou contribuir para mitigar os impactos negativos da urbanização, ou seja, distoante das funções de um espaço livre urbano.

\section{Método empregado para a organização das cartas e das planilhas de espaços} livres

Para o desenvolvimento deste trabalho foram consultadas, preliminarmente, as seguintes fontes:

a) Relação das praças públicas mantidas pela Divisão de Parques e Jardins da Secretaria Municipal de Infra-Estrutura;

b) Cadastro de áreas públicas da Divisão de Desenvolvimento Social da Secretaria Municipal de Planejamento e Gestão Ambiental;

c) Dissertação de mestrado "Estudo dos espaços livres de uso público da cidade de Ribeirão Preto, com ênfase nas áreas verdes e cobertura vegetal de dois setores urbanos" de Perci Guzzo - UNESP, Rio Claro-SP (1999);

d) Carta de espaços livres urbanos públicos de Ribeirão Preto em versão preliminar, organizada pelo Departamento de Gestão Ambiental da Secretaria Municipal de Planejamento e Gestão Ambiental, referente ao ano de 2002.

As unidades urbanísticas tomadas como base para identificar e sistematizar as informações dos espaços livres foram os subsetores urbanos de caráter político-administrativo. Para cada subsetor foram identificados e cartografados os espaços livres que receberam nomenclatura e numeração específica. Para isso tomou-se como base o Mapa do Sistema Viário Geral da Cidade e Sub-Distrito e fez-se o uso do Programa AutoCad versão 2002. Foram geradas as cartas geral e por setor urbano de espaços livres. As informações para cada espaço livre quanto a tamanho, localização, qualificação do nível de implantação, referência cadastral e legislação de criação, quando existente, foram organizadas em planilhas do Programa Excel, divididas por setores e subsetores urbanos. A correspondência entre planilha e carta se dá pela numeração que identifica cada espaço livre. Para a avaliação quanto ao nível de implantação dos espaços livres foram considerados os conhecimentos de campo dos técnicos da Divisão de Parques e Jardins, bem como, visitas às áreas que havia dúvida quanto à sua condição. Para obtenção das áreas em metros quadrados tomou-se como referência a informação disponível 
no cadastro técnico municipal. Quando não disponível, a área foi calculada pelo Programa AutoCad. Finalmente, os espaços livres foram classificados segundo o nível de implantação e a tipologia, de acordo as definições apresentadas anteriormente.

\section{Obtenção do índice de espaços livres públicos}

O índice de espaços livres públicos (IELP) foi obtido a partir da "equação (1)":

IELP = quantidade em metros quadrados de espaços livres com possibilidade de uso público devidamente implantados / população residente em Ribeirão Preto no ano de 2005

O IELP foi calculado considerando também os espaços livres semi-implantados e não implantados, porém o índice que deve ser tomado com referência é aquele calculado para as áreas efetivamente implantadas. Também foi possível obter índice semelhante considerando os espaços livres potencialmente coletivos.

\section{RESULTADOS E DISCUSSÃO}

\section{Espaços livres urbanos públicos e potencialmente coletivos: a situação em Ribeirão Preto}

O Cadastro Municipal de Espaços Livres Urbanos de Ribeirão Preto é constituído de quatro cartas da cidade, dos setores Central/Norte, Leste, Oeste e Sul, com a identificação de cada espaço livre por hachura e numeração que leva em conta a classificação terminológica apresentada no item 2.1. O Cadastro também é constituído de uma extensa planilha com os dados de cada espaço livre. Pela numeração do espaço livre na carta faz-se a busca das informações na planilha. Não apresentamos aqui as cartas ou planilha, considerando a dificuldade de reproduzi-los pela limitação de páginas e do formato do texto.

A "Tabela 1" apresenta, de forma resumida os totais em área de espaços livres públicos e potencialmente coletivos, considerando os cinco setores urbanos da cidade e as quatro categorias de condição de implantação. 
Tabela 1 - Áreas totais em metros quadrados de espaços livres públicos e potencialmente coletivos, considerando os setores urbanos e a condição de implantação - Ribeirão Preto, SP.

\begin{tabular}{|c|c|c|c|c|c|c|}
\hline Setor & Implantada & $\begin{array}{c}\text { Semi- } \\
\text { Implantada }\end{array}$ & $\begin{array}{c}\text { Não } \\
\text { Implantada }\end{array}$ & $\begin{array}{c}\text { Alteração } \\
\text { de Função }\end{array}$ & $\begin{array}{c}\text { Total do } \\
\text { Setor }\end{array}$ & $\begin{array}{c}\text { Total (sem al- } \\
\text { teração.função }\end{array}$ \\
\hline Centro & $73.232,25$ & 0,0 & 0,0 & 0,0 & $73.232,25$ & $73.232,25$ \\
\hline Norte & $1.127 .428,63$ & $482.732,68$ & $1.278 .693,68$ & $151.803,53$ & $3.051 .658,52$ & $2.899 .854,99$ \\
\hline Leste & $524.893,55$ & $495.369,03$ & $2.305 .857,75$ & $54.047,50$ & $3.380 .167,83$ & $3.326 .120,33$ \\
\hline Oeste & $6.072 .514,22$ & $477.576,41$ & $1.087 .054,10$ & $89.660,74$ & $7.726 .805,47$ & $7.637 .144,73$ \\
\hline Sul & $378.317,07$ & $180.047,43$ & $1.067 .991,92$ & $225.707,28$ & $1.852 .063,70$ & $1.626 .356,42$ \\
\hline Total & $8.176 .385,72$ & $1.635 .725,55$ & $5.739 .597,45$ & $521.219,05$ & $16.083 .927,7$ & $15.562 .708,72$ \\
\hline
\end{tabular}

Excetuando o Campus da USP, com área de $5.728 .874 \mathrm{~m}^{2}$ e os espaços livres com alteração de função, com área de 521.219,05 m², obtêm-se 9.833.832,72 $\mathrm{m}^{2}$ que representam os espaços livres urbanos essencialmente públicos e com capacidade de abrigar atividades de lazer da população. Então, deste montante, 24,9\% $\left(2.447 .509,72 \mathrm{~m}^{2}\right)$ são espaços livres públicos implantados; 16,7\% (1.635.725,55 $\left.\mathrm{m}^{2}\right)$ são espaços livres públicos tidos como semiimplantados e 58, 4\% (5.739.597,45 $\left.\mathrm{m}^{2}\right)$ são espaços livres públicos não implantados.

A "Tabela 2" apresenta a quantidade de espaços livres por setor urbano considerando suas tipologias.

Tabela 2 - Quantidade de espaços livres públicos e potencialmente coletivos considerando os setores urbanos e as tipologias empregadas - Ribeirão Preto, SP.

\begin{tabular}{|l|c|c|c|c|c|c|c|c|}
\hline \multicolumn{1}{|c|}{ Setor } & Parque & Praça & $\begin{array}{c}\text { Área } \\
\text { Verde } \\
\text { Pública* }\end{array}$ & $\begin{array}{c}\text { Cemité- } \\
\text { rio }\end{array}$ & $\begin{array}{c}\text { Potencial- } \\
\text { mente } \\
\text { coletivo }\end{array}$ & $\begin{array}{c}\text { Total } \\
\text { geral }\end{array}$ & $\begin{array}{c}\text { Alteração } \\
\text { de função }\end{array}$ & Total \\
\hline Central & - & 7 & - & - & - & 7 & - & 7 \\
\hline Norte & 6 & 51 & 287 & 1 & - & 345 & 30 & 315 \\
\hline Leste & 4 & 55 & 273 & 1 & - & 333 & 2 & 331 \\
\hline Oeste & 4 & 41 & 162 & - & 1 & 208 & 7 & 201 \\
\hline Sul & 3 & 38 & 254 & 1 & - & 296 & 39 & 257 \\
\hline Total geral & 17 & 192 & 976 & 3 & 1 & 1.189 & 78 & 1111 \\
\hline Alt. função & - & 3 & 75 & - & - & 78 & & \\
\hline Total & 17 & 189 & 901 & 3 & 1 & 1.111 & & \\
\hline
\end{tabular}

Os espaços livres públicos e potencialmente coletivos somam 1.189 unidades na área urbana de Ribeirão Preto, considerando o distrito-sede e o sub-distrito de Bonfim Paulista. No entanto, 78 espaços livres foram identificados com alteração de função, alterando o total de unidades para 1.111.

Os espaços livres com alteração de função são áreas verdes e sistemas de lazer ou recreio, destinados em loteamentos e parcelamentos do solo urbano, que atualmente abrigam 
favelas, equipamentos institucionais, tais como creches, escolas, postos de saúde, reservatórios e poços do Departamento de Água e Esgoto de Ribeirão Preto (DAERP). Em alguns casos ocorre apropriação indevida, para fins de recreação particular, da vizinhança, como é o caso de áreas identificadas no Jardim Canadá. As 78 áreas com alteração de função perfazem 521.219,05 $\mathrm{m}^{2}$ e representam 5,3\% da área total de espaços livres públicos. Deve-se alertar para o fato de que uma vez destinadas como área verde pública, essa função original não pode ser alterada. Essa determinação é explicita na Constituição do Estado de São Paulo (Artigo 180, inciso VII) e na Lei Orgânica do Município (Artigo 158, inciso III). Deve-se lembrar que como áreas verdes públicas, também se enquadram os sistemas de lazer e de recreio destinados nos empreendimentos de loteamento e parcelamento do solo urbano.

As praças públicas e os parques urbanos de Ribeirão Preto representam os espaços livres em que há lei e/ou decreto municipal criando-os com tais. Pode-se denominá-los de espaços livres públicos formais da cidade. Embora criados e denominados por lei, nem todos se encontram implantados.

As 189 praças públicas de Ribeirão Preto somam 1.273.267,67 $\mathrm{m}^{2}$ que correspondem a 12,95\% da área de espaços livres públicos da cidade.

Os parques urbanos em Ribeirão Preto somam 1.769.232,81 $\mathrm{m}^{2}$ que correspondem a $18 \%$ da área de espaços livres públicos da cidade. Em área, 30\%, ou 531.520,76 m², não se encontram implantados; $26,4 \%$, ou 467.509,82 $\mathrm{m}^{2}$, encontram-se semi-implantados e 43,5\% , ou 770.202,23 $\mathrm{m}^{2}$, encontram-se implantados. Apenas o Parque Municipal do Morro do São Bento se configura também como unidade de conservação municipal, ou seja, abriga atributos naturais de relevante interesse ecológico para o Município. O parque Francisco Prestes Maia se configura como uma praça pública. O parque Cláudio Franco de Lima, pela sua dimensão e configuração urbanística, quando implantado, se caracterizará, provavelmente, em praça pública. Ambos deveriam ter sua denominação alterada. A "Tabela 3" traz a relação dos parques urbanos de Ribeirão Preto. 
Tabela 3 - Parques urbanos de Ribeirão Preto

\begin{tabular}{|l|l|l|l|}
\hline \multicolumn{1}{|c|}{ Denominação } & \multicolumn{1}{|c|}{$\begin{array}{c}\text { Condição } \\
\text { de implantação }\end{array}$} & \multicolumn{1}{|c|}{$\begin{array}{c}\text { Localização } \\
\text { por setor }\end{array}$} & ${\text { Área em } \mathbf{~ m}^{2}}$ \\
\hline Ecológico Orestes Lopes de Camargo & Não implantado & Norte - N6 & $19.922,76$ \\
\hline Linear Ulisses Guimarães & Não implantado & Norte - N1/N8 & $275.250,50$ \\
\hline Augusto Ruschi & Não implantado & Norte - N10 & $66.682,49$ \\
\hline Roberto de Melo Genaro & Não implantado & Sul - S1 & $11.722,00$ \\
\hline José Maria Morgade de Miranda & Não implantado & Norte - N1 & $54.948,00$ \\
\hline Ecológico Cláudio Franco de Lima & Não implantado & Oeste - O7 & $12.322,00$ \\
\hline Municipal da Mata do Jardim Palmares & Não implantado & Leste - L7 & $90.673,01$ \\
\hline Ecológico e Botânico Ângelo Rinaldi & Semi-implantado & Oeste - O7 & $182.986,17$ \\
\hline Ecológico Ribeirão Verde & Semi-implantado & Leste - L1 & $105.055,65$ \\
\hline Linear Sérgio Mota & Semi-implantado & Leste/Sul - L3,6/S3 & $179.468,00$ \\
\hline Municipal Dr. Luis Carlos Raya & Implantado & Sul - S7 & $39.560,29$ \\
\hline Dr. Fernando de Freitas M. da Silva & Implantado & Sul - S5 & $68.605,59$ \\
\hline Francisco Prestes Maia & Implantado & Oeste - O2 & $12.485,25$ \\
\hline Maurílio Biagi & Implantado & Oeste - O2 & $196.522,31$ \\
\hline Prefeito Luis Roberto Jábali (Curupira) & Implantado & Leste - L3 & $138.700,25$ \\
\hline de Bairro Tom Jobim & Implantado & Norte - N6 & $63.448,54$ \\
\hline Municipal Morro do São Bento & Implantado & Norte - N1 & $250.880,00$ \\
\hline
\end{tabular}

Os três cemitérios somam 251.705,2 $\mathrm{m}^{2}$ que correspondem a 2,56 \% da área de espaços livres públicos da cidade. Finalmente, as 901 áreas verdes públicas perfazem 6.539.627,04 $\mathrm{m}^{2}$ que correspondem a 66,5\% da área de espaços livres públicos da cidade.

\section{Índice de espaços livres públicos para Ribeirão Preto}

A "Tabela 4" traz o índice de espaços livres públicos (IELP) considerando as três categorias de urbanização e a população residente no Município em 2005 (552.630 habitantes).

Tabela 4 - Índices de espaços livres públicos, considerando a condição de implantação.

\begin{tabular}{|l|c|c|}
\hline \multicolumn{1}{|c|}{ Condição de Implantação } & Área disponível & $\begin{array}{c}\text { Índice de espaços livres de uso } \\
\text { público }\end{array}$ \\
\hline Implantado & $2.447 .509,72 \mathrm{~m}^{2}$ & $4,4 \mathrm{~m}^{2} / \mathrm{hab}$ \\
\hline Implantado + Semi-implantado & $4.083 .235,27 \mathrm{~m}^{2}$ & $7,4 \mathrm{~m}^{2} / \mathrm{hab}$ \\
\hline Implantado+ Semi + Não implantado & $9.822 .708,72 \mathrm{~m}^{2}$ & $17,8 \mathrm{~m}^{2} / \mathrm{hab}$ \\
\hline
\end{tabular}

Para o cômputo desse índice deve ser considerado, fundamentalmente, os espaços livres que oferecem condições para o uso público: lazer e convívio social. Assim, dos valores apresentados na "Tabela 4", o índice oficial é 4,4 $\mathrm{m}^{2} / \mathrm{hab}$. Nota-se que há um "estoque" de espaços livres considerável na cidade (distrito sede e sub-distrito) e que se todos eles viessem a ser implantados, o índice chegaria a quase $18 \mathrm{~m}^{2} / \mathrm{hab}$. Esse estoque tem sido chamado também de passivo ambiental de áreas verdes públicas, pois embora estejam destinadas para cumprir suas funções (social, ecológica e estética), ainda não foram devidamente implantados. 
Essas áreas são o alvo do presente trabalho e preocupação da Promotoria de Justiça de Meio Ambiente, motivo de ter sido gerado o Inquérito Civil $n^{0} 268 / 2004$.

Dois trabalhos anteriores a esse, Aquino (1988) e Guzzo (1999), encontraram valores inferiores ao apresentado, empregando terminologia e metodologia semelhantes. Em 1988, Ribeirão Preto tinha $0,7 \mathrm{~m}^{2} / \mathrm{hab}$ de espaços livres públicos e em $1999,2,38 \mathrm{~m}^{2} / \mathrm{hab}$. Isso demonstra que o índice aumentou nos últimos anos. Acredita-se que esse incremento tenha ocorrido, principalmente, pela implantação de novos parques urbanos na última década, tais como: Prefeito Luiz Roberto Jábali (Curupira), Tom Jobim, Luis Carlos Raya e Fernando de Freitas Monteiro da Silva.

Um outro índice que pode ser gerado com os dados apresentados é o de espaços livres potencialmente coletivos. Em Ribeirão Preto, somente o campus da Universidade de São Paulo, faz parte desta tipologia de espaço livre. Se considerarmos toda a extensão do campus (5.728.876 $\left.\mathrm{m}^{2}\right)$, teremos um índice de 10,4 $\mathrm{m}^{2} / \mathrm{hab}$. Excetuando as áreas edificadas do campus, o índice é de 10,3 $\mathrm{m}^{2} / \mathrm{hab}$. Essa grande área verde da cidade é motivo de um estudo a parte, dos mesmo autores, que está presente nestes anais com o título "O Campus da USP como Área Verde no Município de Ribeirão Preto".

A Sociedade Brasileira de Arborização Urbana (SBAU), durante a realização do VI Encontro Nacional sobre Arborização Urbana, em 1996, concluiu e recomendou, em sua assembléia de encerramento, constando da Carta de Londrina e Ibiporã, "o estabelecimento de metodologias que permitam obter o índice per capita de áreas verdes públicas destinadas à recreação, considerando como índice mínimo $15 \mathrm{~m}^{2} /$ hab". Acredita-se que esta é uma referência que pode ser adotada para as cidades brasileiras de um modo geral.

Ainda sobre o emprego do IELP, deve-se levar em conta sua funcionalidade como ferramenta de planejamento com informações condensadas e simplificadas que facilitam a comunicação e auxiliam no processo de decisão, mas que também mascaram disparidades. Assim, os valores numéricos desse indicador, sempre que possível, deve vir associado de uma análise social e urbanística contextualizada.

\section{CONCLUSÕES}

O cadastro ora organizado permite ao poder público local e à comunidade o desenvolvimento de uma política para melhorar o gerenciamento das áreas verdes públicas localizadas no perímetro urbano e quem sabe, saldar o passivo ambiental existente. Da mesma 
maneira, pode subsidiar, em parte, um plano diretor de áreas verdes e arborização urbana do município.

O referido cadastro apresenta a necessidade permanente de atualização. Ainda não foi desenvolvido mecanismo técnico e administrativo eficaz para suprir essa necessidade. Outro ponto frágil do cadastro e a ausência de geo-referenciamento das áreas. Não obstante essas considerações, desde sua finalização, o presente trabalho tem sido usado constantemente por diferentes setores internos da PMRP, órgãos externos e também para fins de pesquisas científicas, demonstrando a sua importância como instrumento urbanístico, de consulta e de planejamento urbano e ambiental.

Diante da legislação citada sobre a alteração de função de áreas verdes públicas, propõe-se a adoção de medidas visando o resgate dessas áreas, quer por meio de desocupação direta ou pela forma de compensação ambiental.

As informações levantadas sobre custos de implantação, manutenção e conservação de áreas verdes públicas por meio de serviços terceirizados, bem como, aquelas referentes às necessidades de estruturação dos setores da PMRP serão motivo de apresentação e discussão em trabalho subseqüente.

\section{AGRADECIMENTOS}

Aos funcionários da Divisão de Informatização e Computação Gráfica Cadastro Técnico da Secretaria Municipal de Planejamento e Gestão Ambiental: Francisco do Carmo Nucitelli, Fábio Passilongo Baiochi e Célio Rodrigues de Araújo.

Ao agrônomo e chefe da Divisão de Parques e Jardins da Secretaria Municipal de InfraEstrutura: Carlos Henrique Alonso Toldo

A todos os colegas funcionários do Departamento de Gestão Ambiental da Secretaria Municipal de Planejamento e Gestão Ambiental.

Á turismóloga e ex-estagiária do Departamento de Gestão Ambiental: Aline Calache.

À ecóloga e estagiária do Departamento de Gestão Ambiental: Carolina Silva Simões.

\section{REFERÊNCIAS BIBLIOGRÁFICAS}

AQUINO, José Augusto. Levantamento das áreas verdes de Ribeirão Preto/SP.Monografia de graduação - UNESP. Rio Claro (SP), 1988. 61 p. 
CAVALHEIRO, Felisberto; DEL PICCHIA, Paulo Celso Dorneles. Áreas verdes: conceitos, objetivos e diretrizes para o planejamento. In: ENCONTRO NACIONAL SOBRE ARBORIZAÇÃO URBANA, 4, 1992, Vitória (ES). Anais...vol. I. Vitória, 1992. p. 29-38.

GOMES, Marcos Antônio Silvestre. As praças de Ribeirão Preto - SP: uma contribuição geográfica ao planejamento e à gestão dos espaços públicos. Dissertação de Mestrado Universidade Federal de Uberlândia. Uberlândia (MG), 2005. 194 p.

GUZZO, Perci. Estudo dos espaços livres de uso público da cidade de Ribeirão Preto/SP, com detalhamento da cobertura vegetal é áreas verdes públicas de dois setores urbanos. Dissertação de Mestrado - UNESP. Rio Claro (SP), 1999. 125 p.

LIMA, Ana Maria Liner Pereira et al. Problemas de utilização na conceituação de termos como espaços livres, áreas verdes e correlatos. In: CONGRESSO BRASILEIRO DE ARBORIZAÇÃO URBANA, 2, São Luís (MA). Anais... São Luís: imprensa EMATER/MA, 1994. p. 539-553.

RIBEIRÃO PRETO. Prefeitura Municipal. Lei Orgânica do Município. Ribeirão Preto, SP, 1989. Disponível em: <http://www.ribeiraopreto.sp.gov.br>. Acesso em 21 set. 2006.

RIBEIRÃO PRETO. Prefeitura Municipal. Cadastro Municipal de Espaços Livres Urbanos e Estudos para Implantação, Manutenção e Conservação das Áreas Verdes Públicas em Ribeirão Preto, SP. Relatório técnico das secretarias municipais de Planejamento e Gestão Ambiental e de Infra-Estrutura. Ribeirão Preto, SP, 2005. 